\title{
Electrostatically Driven Guest Binding in Self- Assembled Porous Network at the Liquid/Solid Interface
}

Kohei Iritani, ${ }^{\dagger}{ }^{\circledR}$ Motoki Ikeda, ${ }^{\dagger}$ Anna Yang, ${ }^{\ddagger}$ Kazukuni Tahara ${ }^{\dagger, \S}$ Masaru Anzai, ${ }^{\S}$ Keiji Hirose, ${ }^{\dagger}$ Steven De Feyter," Jeffrey S. Moore, ${ }^{\ddagger, *}$ Yoshito Tobe ${ }^{\dagger, \perp, *}$

${ }^{\dagger}$ Division of Frontier Materials Science, Graduate School of Engineering Science, Osaka University, Toyonaka, Osaka 560-8531, Japan, ${ }^{\ddagger}$ Departments of Chemistry and Beckman Institute for Advanced Science and Technology, University of Illinois at Urbana Champaign, Urbana, Illinois 61801, United States, ${ }^{\S}$ Department of Applied Chemistry, School of Science and Technology, Meiji University, Kawasaki, Kanagawa 214-8571, Japan, "Department of Chemistry, KU Leuven - University of Leuven, Celestijnenlaan 200F, 3001 Leuven, Belgium. ${ }^{\perp}$ The Institute of Scientific and Industrial Research, Osaka University, 8-1, Mihogaoka, Ibaraki, Osaka 567-0047, Japan

ฯ Present address: Department of Applied Chemistry, School of Engineering, Tokyo University of Technology, Hachioji, Tokyo 192-0982, Japan

*To whom correspondence should be addressed. E-mail: jsmoore@illinois.edu (J.S.M.); tobe@chem.es.osaka-u.ac.jp (Y.T.). 


\section{ABSTRACT}

We present here the construction of a self-assembled two-dimensional (2D) porous monolayer bearing a highly polar 2D space to study guest co-adsorption through electrostatic interactions at the liquid/solid interface. For this purpose, a dehydrobenzo[12]annulene (DBA) derivative, DBA-TeEG, having tetraethylene glycol (TeEG) groups at the end of the three alternating alkoxy chains connected by $p$-phenylene linkers was synthesized. As a reference host molecule, DBA-C10 having non-polar $\mathrm{C}_{10}$ alkyl chains, at three alternating terminals was employed. As guest molecules, hexagonal phenylene-ethynylene macrocycles (PEMs) attached by triethylene glycol (TEG) ester and hexyl ester groups, PEM-TEG and PEM-C6, respectively, at each vertex of the macrocyclic periphery were used. STM observations at the 1,2,4-trichlorobenzene/HOPG interface revealed that PEM-TEG was immobilized in the pores formed by DBA-TeEG at higher probability due to electrostatic interactions such as dipole-dipole and hydrogen bonding interactions between oligoether units of the host and guest, in comparison to PEM-C6 with non-polar groups. These observations are discussed based on molecular mechanics simulations to investigate the role of the polar functional groups. When a nonpolar host matrix formed by DBA-C10 was used, however, only phase separation and preferential adsorption were observed; virtually no host-guest complexation was discernible. This is ascribed to the strong affinity between the guest molecules which form by themselves densely packed van der Waals networks on the surface. 


\section{INTRODUCTION}

Two-dimensional (2D) molecular assembly on solid surfaces has become a subject of keen interest because of prospects in the field of nanoscience and nanotechnology such as molecular-scale electronics, highly selective sensors, and tailor-made catalyses. ${ }^{1-5}$ Among various 2D structures, porous networks attract a great deal of interest because various molecules and molecular clusters can be immobilized in the surface-confined pore space as guests in size-, shape-, symmetry-, and functionselective manner. ${ }^{6-10}$ In most cases, the main driving forces for guest immobilization in the pores are vertical van der Waals interactions between a guest molecule and the substrate surface in addition to lateral van der Waals interactions between the periphery of a guest molecule and the edge of the 2D pore; the latter frequently serve to generate selectivity. In this respect, matching in size and shape between a guest molecule and the $2 \mathrm{D}$ porous space plays a very important role for guest binding. To gain crucial information on the host-guest events on surfaces, scanning tunneling microscopy (STM) has been used as a powerful tool by visualizing the molecular assemblies with sub-molecular level under ultrahigh vacuum conditions as well as the liquid/solid interfaces. ${ }^{11-13}$

In view of prospects in nanoscale patterning and sensing based on host-guest recognition, the modification of not only the physical environment such as the size and shape of pores but also the chemical environment to bind a specific guest molecule via guest-specific noncovalent interactions is one of the challenges in this field. For example, binding small positively charged ions ${ }^{14-19}$ and 
negatively charged species ${ }^{20,21}$ has been reported. However, for immobilization of neutral organic guests, although a few studies on the size- and shape-modification of the 2D pores with spacecontrolling groups have been reported, ${ }^{22-25}$ little has been done for chemical modification of pore space. Recently, we demonstrated the construction of porous space modified by fluoroalkyl groups of a honeycomb type network formed by a dehydrobenzo[12]annulene (DBA) and its guest recognition ability toward guests via fluorophilicity at the liquid/solid interface. ${ }^{26}$ In order to study host-guest binding driven by other intermolecular interactions at the solid/liquid interface, we describe herein the construction of polar pores outlined with oligoethylene glycol (OEG) units which possess a permanent dipole moment. ${ }^{27,28}$ In three dimensional (3D) space, OEG groups have been used to create a polar environment in which guest molecules are immobilized by dipole-dipole interactions. $^{29-31}$ However, the construction of $2 \mathrm{D}$ pores that can bind a guest molecule by electrostatic interactions has not been reported yet.

For the construction of 2D pores equipped with OEG units at the liquid/solid interface, we planned to use a supramolecular honeycomb structure of a DBA derivative as a host matrix. To this end, we designed and synthesized DBA-TeEG (Figure 1a). To place three tetraethylene glycol (TeEG) units at the periphery of the pore, the TeEG unit was connected by a para-phenylene linker at the end of a $\mathrm{C}_{10}$ alkyl chain. The three other alkyl chains were tetradecyloxy groups $\left(\mathrm{C}_{14}\right)$. As a reference host molecule, DBA-C10 ${ }^{26}$ having non-polar $\mathrm{C}_{10}$ alkyl chains, instead of polar TeEG groups, at three 
alternating terminals was employed. As guest molecules, two phenylene-ethynylene macrocycles (PEMs), PEM-TEG ${ }^{32}$ having six peripheral triethylene glycol (TEG) units and PEM-C6 ${ }^{33}$ surrounded by six $\mathrm{C}_{6}$ alkyl chains, respectively, were chosen (Figure 1a). 1,2,4-Trichlorobenzene (TCB) was used as a solvent in view of its moderate affinity to both polar and nonpolar host/guest molecules to minimize bias due to solvent polarity. Prior to experiments, molecular modeling studies indicated that the porous space formed by DBA-TeEG is not large enough to accommodate a guest with extended side chains, suggesting that the side chains of either the host matrix (the TeEG units) or the guest molecules (the TEG or $\mathrm{C}_{6}$ units) may not be adsorbed on the surface, but exposed to the solution phase (Figure 2).

It should be pointed out, however, that the guest molecules, PEM-TEG and PEM-C6, are capable of forming self-assembled networks of their own. In the previous study, ${ }^{33}$ we revealed that PEMTEG formed dense packed monolayers (tentatively called dense hexagonal and zigzag structures) on the surface stabilized by hydrogen bonds between the carbonyl oxygen and aromatic hydrogen atoms. The TEG units did not adsorb on the HOPG surface. PEM-C6 formed a honeycomb structure driven by van der Waals interactions between the interdigitated alkyl chains of neighboring molecules at the liquid/solid interface. Therefore, PEM-TEG and PEM-C6 would not only act as guest molecules but also assemble by themselves in competition with the networks of the host molecules. Indeed, there are a few examples of co-existence of host-guest events and phase separation in bicomponent 
systems. ${ }^{34-36}$ In binary systems, there are following four possible outcomes of the phase behavior; (1) phase segregation, ${ }^{37-39}$ (2) preferential adsorption, ${ }^{40-42}$ (3) random mixing, ${ }^{43-45}$ and (4) cocrystallization. ${ }^{14,26,46-50}$ Phase segregation means co-existence of domains of host networks and guest networks in the present case. The host-guest networks in which a guest molecule is co-adsorbed in the pores without affecting the host network structure ${ }^{9,10,51-56}$ can be regarded as preferential adsorption of a host. Though co-crystallization including cooperative interactions of both components is principally possible in view of the presence of the phenylene-ethynylene units as a common scaffold in both host and guest molecules, it is unlikely because of the mismatch in the chain lengths. As a consequence, we report here not only the host-guest events but also the phase behavior in the binary system consisting of DBAs and PEMs (Figure 2), and the controlling factors that govern the outcome of molecular assembly at the liquid/solid interface.
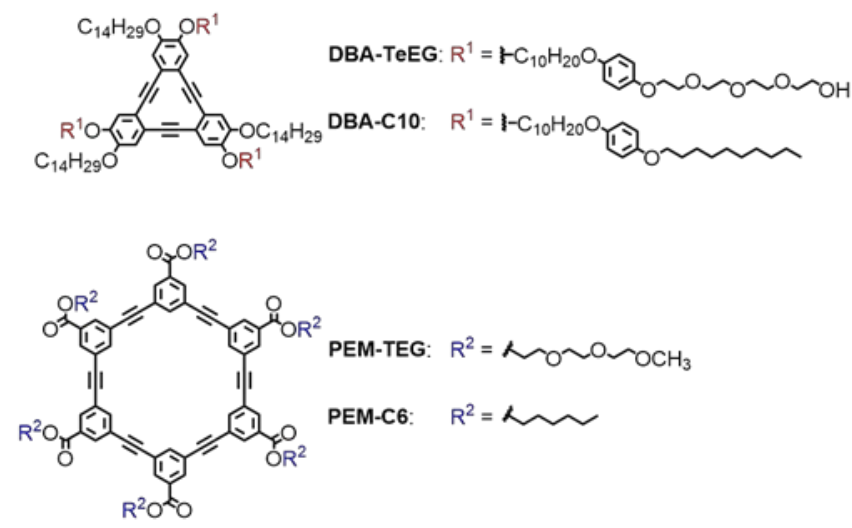

Figure 1. Chemical structures of DBA-TeEG, DBA-C10, ${ }^{26}$ PEM-TEG, ${ }^{32}$ and PEM-C6. ${ }^{33}$ 

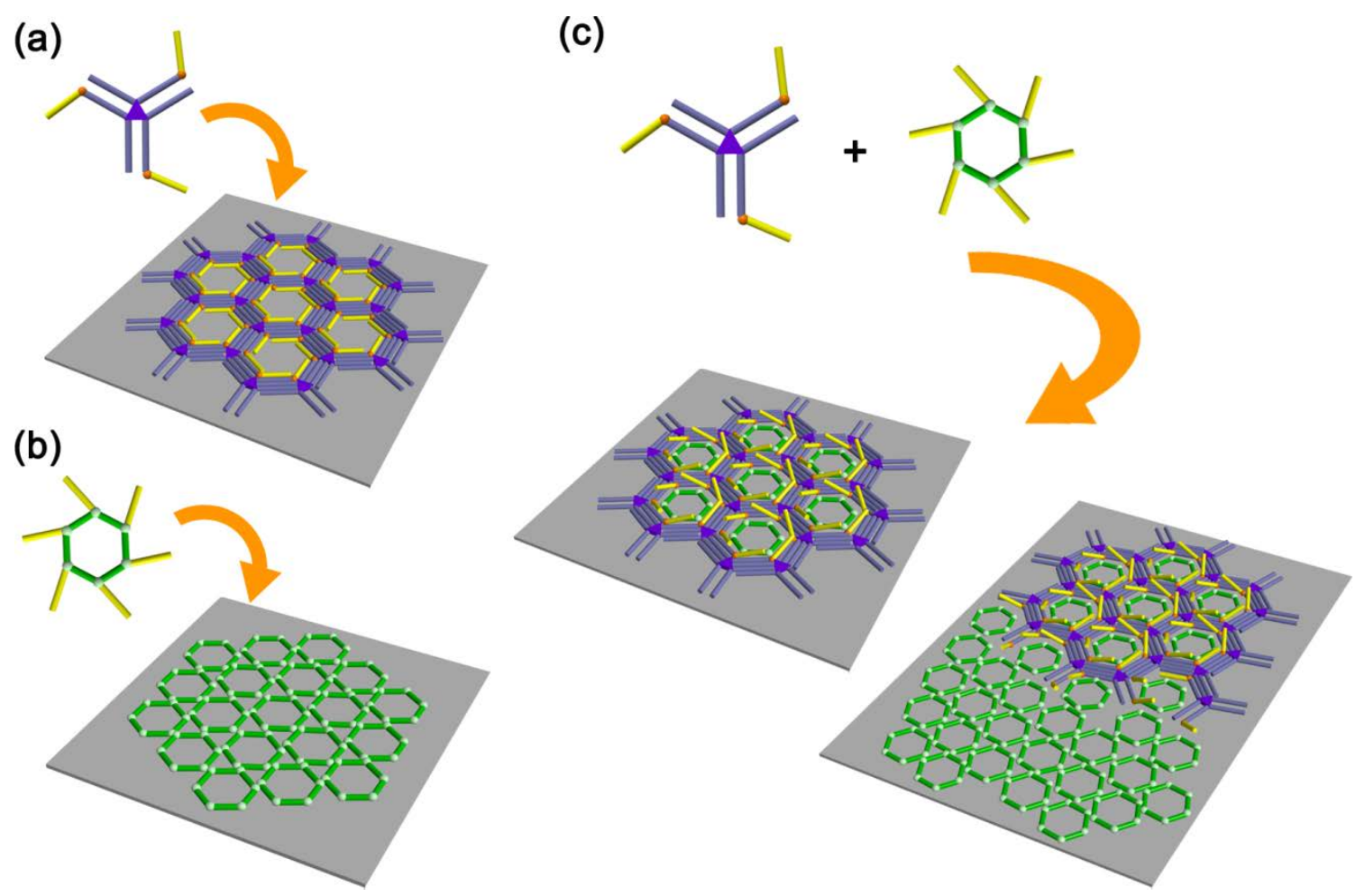

Figure 2. Schematic models for the formation of a honeycomb type network of DBAs (a) and a dense packed network of PEMs (b), and host-guest event and phase behavior in binary system (c) by selfassembly on a surface. In the networks, the side-chains of PEMs are omitted for clarity reason.

\section{EXPERIMENTAL SECTION}

Synthesis. Syntheses of DBA-C10, ${ }^{26}$ PEM-TEG, ${ }^{32}$ and PEM-C6 ${ }^{33}$ were reported previously.

DBA-TeEG was prepared by the same method as that reported for DBA-C10 (See Supporting Information).

Details of STM Observations at the Liquid/Solid Interface. All experiments were performed at 23-27 ${ }^{\circ} \mathrm{C}$ using a Nanoscope IIIa (Digital Instruments Inc.) or a Nanoscope V (Bruker AXS) with an 
external pulse/function generator (Agilent 33220A) with negative sample bias. All STM images were acquired in the constant current mode. Tips were mechanically cut from $\mathrm{Pt} / \mathrm{Ir}$ wire (80\%/20\%, diameter $0.25 \mathrm{~mm}$ ). During scanning, electric pulses from -1.6 to $-2.8 \mathrm{~V}$ with a pulse width of 880 ns were occasionally applied using a pulse/function generator to clean the point end of an STM tip.

Prior to imaging, compounds were dissolved in commercially available 1,2,4-trichlorobenzene (TCB) at several solute concentrations described in the text. Immediately before use, highly oriented pyrolytic graphite (HOPG) substrate (grade ZYB, Momentive Performance Material Quartz Inc., Strongsville, $\mathrm{OH}$ ) was cleaved using adhesive tape. A homemade liquid cell placed on HOPG substrate was employed to minimize the effect of solvent evaporation using a sample solution of 30 $\mu \mathrm{L}$. All STM observations of the monolayers were performed at the interface between TCB and HOPG after the solution was subjected to the cell without annealing treatment within a $3 \mathrm{~h}$ period or after annealing treatment at $70{ }^{\circ} \mathrm{C}$ for $1 \mathrm{~h}$ in an oven to attain thermodynamic equilibrium. ${ }^{57} \mathrm{By}$ changing the tunneling parameters during the STM imaging, namely, the voltage applied to the underlying HOPG substrate, it was possible to switch from the visualization of the adsorbate layer to that of the substrate. This enabled us to correct for drift effects by the use of SPIP (scanning probe image processer) software (version 6.2.4., Image Metrology A/S, Hørsholm). Unit cell parameters are determined from more than 30 experimental values of at least two calibrated STM images. 
Details of Molecular Mechanics Simulations. Molecular mechanics (MM) simulations were performed with the Materials Studio 8.0 using the Forcite module with COMPASS force field. The initial structures of monolayers were built from the respective molecular models which were optimized by the semiempirical PM3 method. Then, the orientation of the alkyl chains relative to the $\pi$-system was adjusted based on that observed in the STM images. The molecules were placed 0.35 $\mathrm{nm}$ above the first layer of a periodic two-layer sheet of graphene with an interlayer distance of 0.335 nm to mimic graphite. The two-layer graphene structure was frozen during the simulations, and a cutoff of $2.0 \mathrm{~nm}$ was applied for the van der Waals interactions (Lennard-Jones type). Periodic boundary conditions (PBC) for simulations are described in the figure captions. 


\section{RESULTS AND DISCUSSION}

\section{STM observations of monolayers formed by DBA-TeEG or DBA-C10 at the TCB/graphite}

interface. A high resolution STM image of a self-assembled monolayer formed by DBA-TeEG at the TCB/HOPG interface $\left(1.0 \times 10^{-5} \mathrm{M}\right)$ after annealing treatment at $70^{\circ} \mathrm{C}$ for $1 \mathrm{~h}$ is shown in Figure 3a. A large-scale image is given in Figure S1a. In the STM image, the triangular shaped bright features correspond to the conjugated cores of DBA-TeEG, while the darker parts between the DBA cores are assigned to four interdigitated alkyl chains, ${ }^{58}$ revealing the formation of a honeycomb structure. Small bright features located at the corners of the pores correspond to the phenylene linkers (indicated by the yellow arrow in Figure 3a). The dim fuzzy rods at the rim of the pores indicated by the green arrow in Figure 3a are assigned to the TeEG units, though they are not visualized clearly, probably due to the low tunneling efficiency of the ethylene glycol units ${ }^{59,60}$ or the mobility owing to weak interactions with the HOPG substrate. ${ }^{61}$ Unit cell parameters are $a=b=5.0 \pm 0.1 \mathrm{~nm}, \gamma=60 \pm 1^{\circ}$. In some of the pores, dim fuzzy features are observed, which are ascribed to a self-adsorbed ${ }^{62}$ DBATeEG molecule or co-adsorbed TCB molecules. Figure 3b displays a molecular model built by molecular mechanics (MM) simulations of the honeycomb structure of DBA-TeEG in which six TeEG units were placed in the pores.

STM observation of a self-assembled monolayer formed by DBA-C10 $\left(1.0 \times 10^{-5} \mathrm{M}\right.$ in TCB) after annealing revealed a similar honeycomb structure wherein the phenylene linkers and the terminal 
alkyl chains placed at the rim of the pores are clearly visualized (Figures 3c and S1b). A network model optimized by MM simulations is displayed in Figure 3d. The unit cell parameters $(a=b=5.0$ $\pm 0.1 \mathrm{~nm}, \gamma=60 \pm 1^{\circ}$ ) were identical to those of the honeycomb structure of DBA-TeEG, indicating that the terminal groups in the DBAs (TeEG and $\mathrm{C}_{10}$ alkyl) do not participate in the honeycomb network formation. 

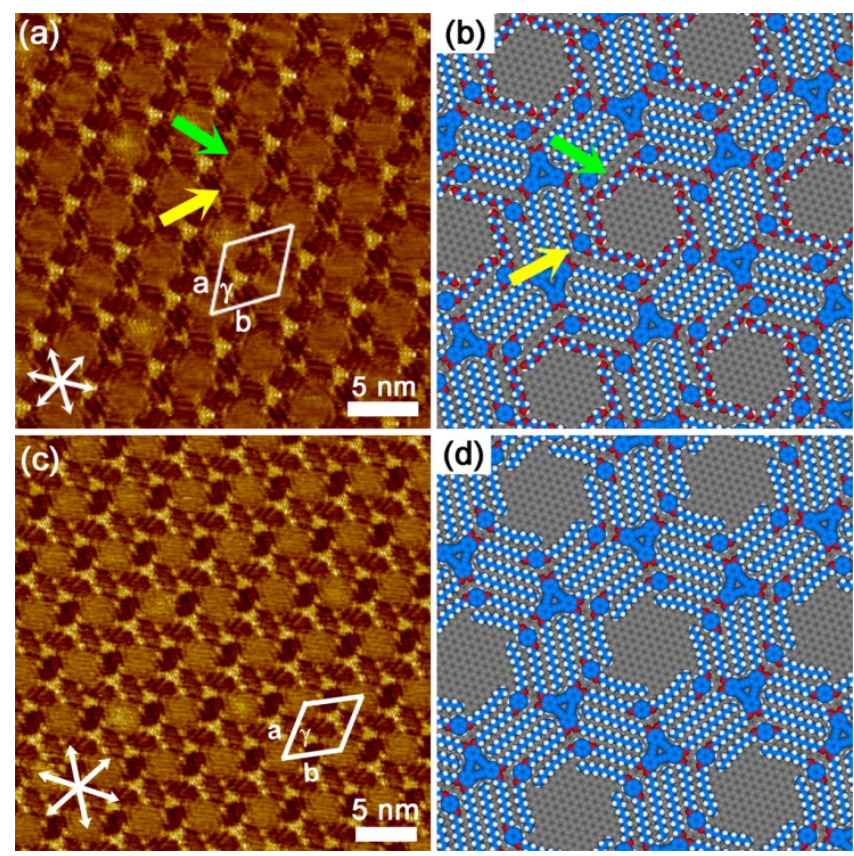

Figure 3. STM images and molecular models of honeycomb structures of DBA-TeEG (a, b) and DBA-C10 (c, d) formed after annealing at $70{ }^{\circ} \mathrm{C}$ for $1 \mathrm{~h}$ at the TCB/graphite interface (concentration $=1.0 \times 10^{-5} \mathrm{M}$, tunneling parameters: $I_{\text {set }}=28 \mathrm{pA}$ and $V_{\text {set }}=-88 \mathrm{mV}$ for a and $I_{\text {set }}=41 \mathrm{pA}$ and $V_{\text {set }}=$ $-200 \mathrm{mV}$ for $\mathrm{c}$ ). White arrows indicate the directions of the main symmetry axes of underlying graphite, and yellow and green arrows in (a) and (b) indicate the small feature corresponding to the phenylene linker and the dim fuzzy rod due to the TeEG unit, respectively. Unit cell parameters for both structures are $a=b=5.0 \pm 0.1 \mathrm{~nm}, \gamma=60 \pm 1^{\circ}$. Molecular models were optimized by MM simulations on a graphene bilayer under periodic boundary conditions (PBC): $a=b=4.97 \mathrm{~nm}, \gamma=$ 60.0 $0^{\circ}$ Color code for atoms: blue; C of DBA-TeEG and DBA-C10 molecules, grey; C of the graphene bilayer, red; $\mathrm{O}$, white; $\mathrm{H}$. 


\section{STM observations of monolayers formed by a mixture of DBA-TeEG and PEM-TEG at the}

TCB/graphite interface. Figures 4 displays STM images of a self-assembled monolayer of a mixture of DBA-TeEG $\left(1.0 \times 10^{-5} \mathrm{M}\right)$ and PEM-TEG $\left(1.0 \times 10^{-5} \mathrm{M}\right)$ in a $1: 1$ molar ratio at the TCB/HOPG interface after annealing. STM images before annealing are shown in Figure S2. In both cases, the surface was covered by the honeycomb structure formed by DBA-TeEG and in some of the pores PEM-TEG molecules were observed as cyclic features. The unit cell parameters of the honeycomb structure $\left(a=b=5.0 \pm 0.1 \mathrm{~nm}, \gamma=60 \pm 1^{\circ}\right)$ were identical to those of the network formed by DBATeEG alone, indicating that co-adsorption of PEM-TEG does not affect the host network structure. The pore spaces are classified into four categories, according to appearance: filled pore containing a single PEM-TEG molecule which is observed as an apparent cyclic feature, partly filled pore in which an incomplete cyclic feature is observed, fuzzy pore with a fuzzy feature, and open pore in which any bright features are observed (Figure 4c). These pores are indicated by red, green, yellow, and white hexagons, respectively, in Figures 4d and S2c. From a statistical analysis of the STM images before annealing, the distribution of these types of pores was determined to be $42 \%$ for filled pores, $7 \%$ for partly filled pores, $2 \%$ for fuzzy pores, and $49 \%$ for open pores (Table 1 ). Annealing did not change the distribution significantly; 40\% filled pores, 3\% partly filled pores, $4 \%$ fuzzy pores, and 52\% open pores. 


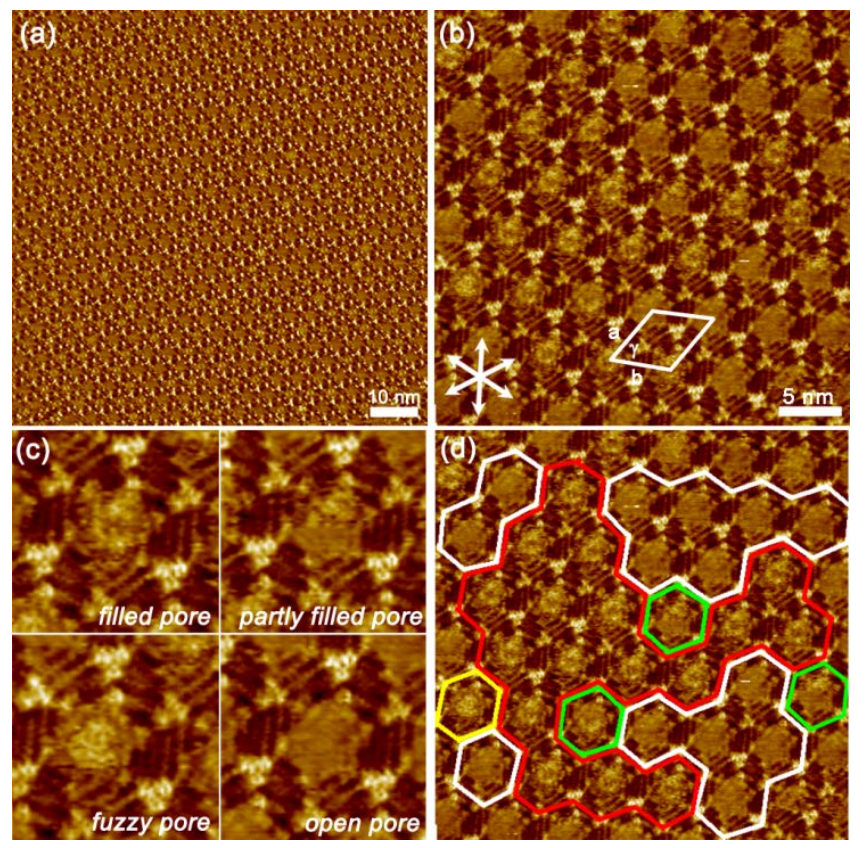

Figure 4. (a, b) STM images of monolayers formed by a mixture of DBA-TeEG and PEM-TEG (each $1.0 \times 10^{-5} \mathrm{M}$ ) after annealing at $70{ }^{\circ} \mathrm{C}$ for $1 \mathrm{~h}$ at the $\mathrm{TCB} /$ graphite interface (tunneling parameters: $I_{\text {set }}=32 \mathrm{pA}$ and $V_{\text {set }}=-60 \mathrm{mV}$ for a, $I_{\text {set }}=26 \mathrm{pA}$ and $V_{\text {set }}=-160 \mathrm{mV}$ for b). Unit cell parameters are $a=b=5.0 \pm 0.1 \mathrm{~nm}, \gamma=60 \pm 1^{\circ}$. White arrows indicate the directions of the main symmetry axes of underlying graphite. (c) Representative images for filled pore, partly filled pore, fuzzy pore, and open pore. (d) The same STM images as b with the color-coded hexagons: red; filled pores, green; partly filled pores, yellow; fuzzy pores, and white; open pores.

When the ratio of PEM-TEG relative to DBA-TeEG was increased to $2.6\left(1.0 \times 10^{-5} \mathrm{M}\right.$ for DBATeEG and $2.6 \times 10^{-5} \mathrm{M}$ for PEM-TEG), the phase segregation between the domains of the honeycomb structure of DBA-TeEG, containing immobilized PEM-TEG as a guest, and those of 
closely packed structures of PEM-TEG was observed regardless of the annealing treatment (Figures S3a and S4a). The relative area of the domains, however, was different before and after annealing. By analysis of 14 STM images of a $100 \times 100 \mathrm{~nm}^{2}$ area, the areas of the domains of the monolayers of DBA-TeEG and PEM-TEG were estimated to be approximately $1: 1$ before annealing, whereas the populations changed to $3: 7$ after annealing (determined from 6 STM images of a $100 \times 100 \mathrm{~nm}^{2}$ area). In the honeycomb structure of DBA-TeEG (Figures S3b, S3c before annealing, and S4b, S4c after annealing), the guest occupancy was determined by statistical analyses before and after annealing (Table 1). For example, the proportions of filled pores were $47 \%$ and $60 \%$ before and after annealing, respectively. The distribution of filled pores did not increase significantly in spite of the increased ratio of PEM-TEG, because the concentration of the guest does not increase as much due to its adsorption on HOPG forming domains consisting solely of the guest.

In the domain of the self-assembled monolayer of PEM-TEG, two different types of 2D patterns, dense hexagonal and zig-zag patterns, ${ }^{33}$ were observed irrespective of annealing treatment (Figures S5a, S5b before annealing, and S5c, S5d after annealing). These patterns are identical to those observed by self-assembly of PEM-TEG under similar conditions as reported previously. ${ }^{33}$ Figures S5e, S5f show molecular models of the dense hexagonal and zigzag structures, respectively, of a PEM derivative in which the TEG ester groups are replaced by ethyl groups. The molecules are connected by hydrogen bonds between the ester carbonyl oxygen and the aromatic hydrogen atoms of 
neighboring molecules.

\section{STM observations of monolayers formed by a mixture of DBA-TeEG and PEM-C6 at the}

TCB/graphite interface. In order to investigate the effect of the polarity of the guest molecule, STM observations of a self-assembled network formed by a mixture of DBA-TeEG $\left(1.0 \times 10^{-5} \mathrm{M}\right)$ and PEM-C6 $\left(1.0 \times 10^{-5} \mathrm{M}\right)$ was performed in a $1: 1$ molar ratio in TCB. Before annealing treatment (Figure 5a), phase segregation between the domains of the honeycomb structure of DBA-TeEG and a self-assembled monolayer of PEM-C6 ${ }^{33}$ was observed in an approximate ratio of $7: 3$ (estimated from 6 images of a $100 \times 100 \mathrm{~nm}^{2}$ area and 2 images of a $200 \times 200 \mathrm{~nm}^{2}$ area). By contrast, after annealing (Figure S6) the surface coverage of a monolayer formed by PEM-C6 increased to more than $95 \%$ (from 9 images of a $100 \times 100 \mathrm{~nm}^{2}$ area and 4 images of a $200 \times 200 \mathrm{~nm}^{2}$ area). Thus, after annealing treatment, PEM-C6 was adsorbed preferentially over DBA-TeEG.

In the domain of the honeycomb structure of DBA-TeEG (Figures 5b, 5c), the guest occupancy distribution was determined as follows: $9 \%$ filled pores, 3\% partly filled pores, $4 \%$ fuzzy pores, and 84\% open pores (Table 1). The distribution of co-adsorbed guest (PEM-C6) in the pores decreased significantly in comparison with the case of PEM-TEG guest. Figures S7 and S6b show STM images of domains consisting of PEM-C6 observed before and after annealing, respectively. The network pattern is assigned to a honeycomb structure of PEM-C6 containing self-adsorbed PEM-C6 
molecules in some of the pores, as described in our previous report. ${ }^{33}$
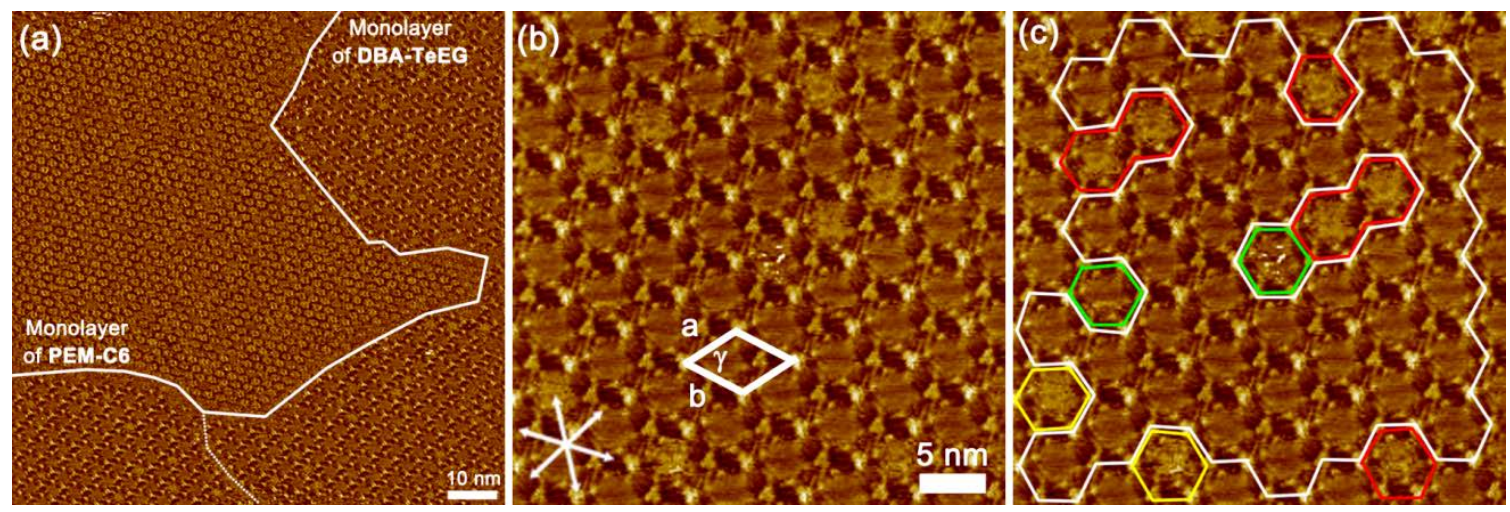

Figure 5. (a, b) STM images of monolayers formed by DBA-TeEG $\left(1.0 \times 10^{-5} \mathrm{M}\right)$ and PEM-C6 $(1.0$

$\times 10^{-5} \mathrm{M}$ ) before annealing at the TCB/graphite interface (tunneling parameters: $I_{\text {set }}=61 \mathrm{pA}$ and $V_{\text {set }}$ $=-320 \mathrm{mV}$ ). Unit cell parameters of the honeycomb structure of DBA-TeEG are $a=b=5.0 \pm 0.1$ $\mathrm{nm}, \gamma=60 \pm 1^{\circ}$. White lines indicate the domain boundaries between the monolayers of DBA-TeEG and PEM-C6. White dotted lines and arrows indicate the domain boundaries of the honeycomb structure of DBA-TeEG and the directions of the main symmetry axes of underlying graphite, respectively. (c) The same STM image as (b), in which red, green, yellow, and white hexagons indicate filled pores, partly filled pores, fuzzy pores, and open pores, respectively. 
STM observations of monolayers formed by a mixture of DBA-C10 and PEM-TEG at the TCB/graphite interface. Next, STM observations using a $1: 1$ mixture of DBA-C10 $\left(1.0 \times 10^{-5} \mathrm{M}\right)$ and PEM-TEG $\left(1.0 \times 10^{-5} \mathrm{M}\right)$ were performed (Figure S8 before annealing and Figure 6 after annealing). In both cases, a honeycomb structure formed by DBA-C10 with PEM-TEG barely coadsorbed in the pores was observed. The unit cell parameters are $a=b=5.0 \pm 0.1 \mathrm{~nm}, \gamma=60 \pm 1^{\circ}$, which are identical to those of the honeycomb structure of DBA-C10. No self-assembled monolayer of PEM-TEG was observed, indicating the preferential adsorption of DBA-C10. Statistical analyses of the distribution of the pores showed $<1 \%$ filled pores, $<1 \%$ partly filled pores, $1-2 \%$ fuzzy pores, and $97 \%$ open pores for the both conditions (Table 1). 

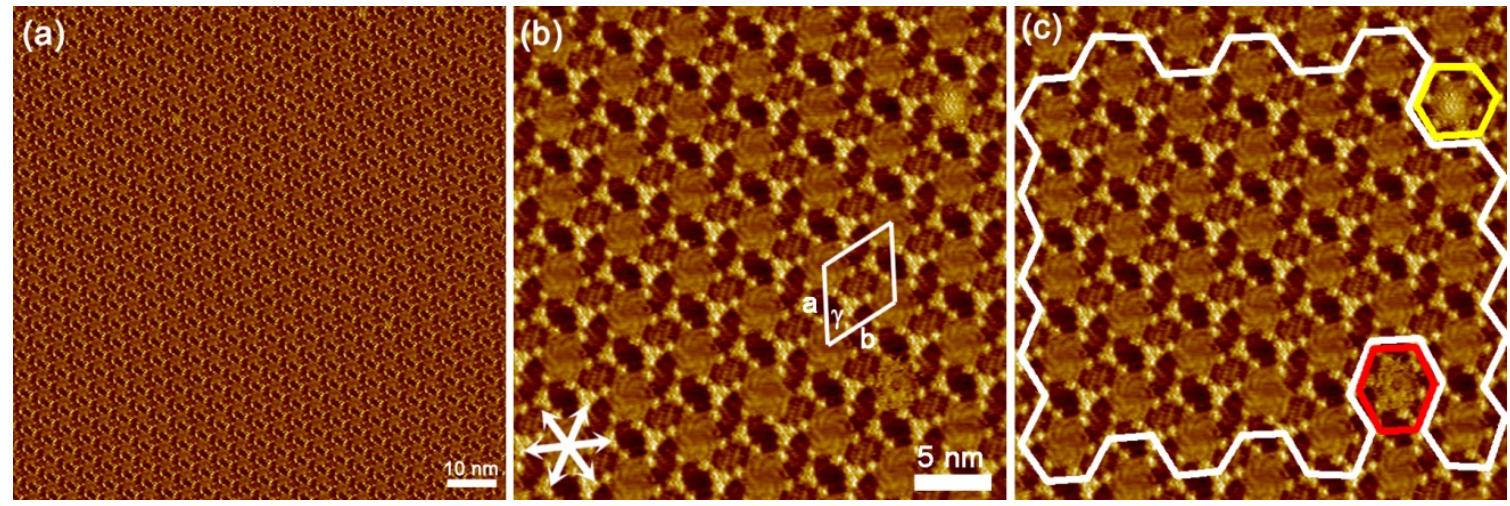

Figure 6. (a, b) STM images of monolayers formed by a mixture of DBA-C10 $\left(1.0 \times 10^{-5} \mathrm{M}\right)$ and

PEM-TEG $\left(1.0 \times 10^{-5} \mathrm{M}\right)$ after annealing at $70^{\circ} \mathrm{C}$ for $1 \mathrm{~h}$ at the TCB/graphite interface (tunneling parameters: $I_{\text {set }}=41 \mathrm{pA}$ and $V_{\text {set }}=-210 \mathrm{mV}$ for a, $I_{\text {set }}=40 \mathrm{pA}$ and $V_{\text {set }}=-189 \mathrm{mV}$ for b). Unit cell parameters of the honeycomb structure of DBA-C10 are $a=b=5.0 \pm 0.1 \mathrm{~nm}, \gamma=60 \pm 1^{\circ}$. White arrows indicate the directions of the main symmetry axes of underlying graphite. (c) The same STM images as (b), in which red, yellow, and white hexagons indicate filled pores, fuzzy pores, and open pores, respectively.

By increasing the molar ratio of PEM-TEG to 2.6 relative to DBA-C10, phase segregation was observed as shown in Figures 7a (after annealing) and S9a (before annealing). The domains of the honeycomb structure of DBA-C10 and the self-assembled monolayers of PEM-TEG were found in an approximate ratio of $7: 3$ (estimated from 10 STM images of a $100 \times 100 \mathrm{~nm}^{2}$ area) before annealing. However, the ratio changed to approximately $3: 7$ (estimated from 16 STM images of a $100 \times 100 \mathrm{~nm}^{2}$ area) after annealing. Figures S9b-c and 7b-c show STM images of the honeycomb 
structure of DBA-C10 observed before and after annealing, respectively. Analyses of STM images revealed $1-2 \%$ filled pores, $2-3 \%$ partly filled pores, $4 \%$ for fuzzy pores, and $92 \%$ for open pores (Table 1). In the domains of PEM-TEG, the dense hexagonal and zigzag structures were observed (Figure S10). ${ }^{33}$
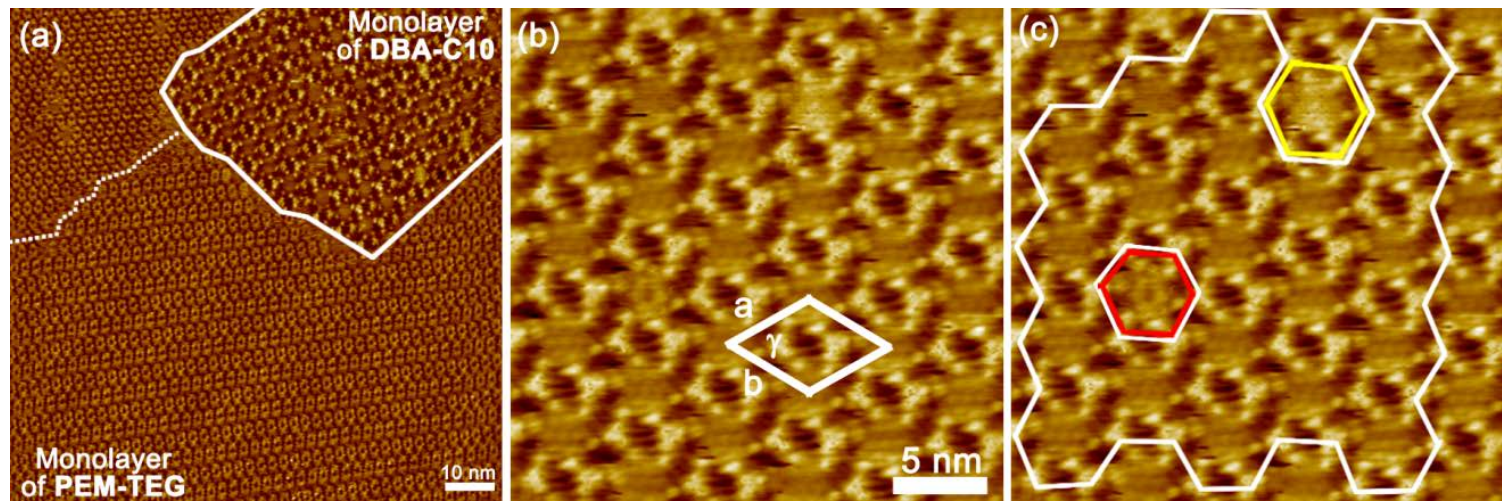

Figure 7. (a, b) STM images of monolayers formed by a mixture of DBA-C10 $\left(1.0 \times 10^{-5} \mathrm{M}\right)$ and PEM-TEG $\left(2.6 \times 10^{-5} \mathrm{M}\right)$ after annealing at $70{ }^{\circ} \mathrm{C}$ for $1 \mathrm{~h}$ at the TCB/graphite interface (tunneling parameters: $I_{\text {set }}=55 \mathrm{pA}$ and $V_{\text {set }}=-330 \mathrm{mV}$ for a, $I_{\text {set }}=52 \mathrm{pA}$ and $V_{\text {set }}=-550 \mathrm{mV}$ for b). Unit cell parameters of the honeycomb structure of DBA-C10 are $a=b=5.0 \pm 0.1 \mathrm{~nm}, \gamma=60 \pm 1^{\circ}$. White lines indicate the domain boundaries between the monolayers of DBA-C10 and PEM-TEG. White dotted lines and arrows indicate the domain boundaries of the honeycomb structure of DBA-C10 and the directions of the main symmetry axes of underlying graphite, respectively. (c) The same STM images as (b), in which red, yellow, and white hexagons indicate filled pores, fuzzy pores, and open pores, respectively. 
STM observations of monolayers formed by a mixture of DBA-C10 and PEM-C6 at the TCB/graphite interface. Finally, we investigated the self-assembly of a $1: 1$ mixture of DBA-C10 $\left(1.0 \times 10^{-5} \mathrm{M}\right)$ and PEM-C6 $\left(1.0 \times 10^{-5} \mathrm{M}\right)$. Similar to the case of the mixture of DBA-TeEG and PEM-C6, the phase segregation between domains of the honeycomb structures formed by DBA-C10 and PEM-C6 was observed (Figure 8a) with an area ratio of approximately 9:1 before annealing (9 images of a $100 \times 100 \mathrm{~nm}^{2}$ area and 3 images of a $200 \times 200 \mathrm{~nm}^{2}$ area). Figure S11 shows an STM image of the honeycomb structures of DBA-C10 and PEM-C6. Analysis of the pores showed no filled pores or partly filled pores; $98 \%$ of open pores (Table 1). In contrast, annealing treatment changed the phase distribution significantly and the honeycomb structure of PEM-C6 was observed preferentially (Figures 8b and S12) with the surface coverage of more than 95\% (5 images of a 100 $\times 100 \mathrm{~nm}^{2}$ area and 5 images of a $200 \times 200 \mathrm{~nm}^{2}$ area). 


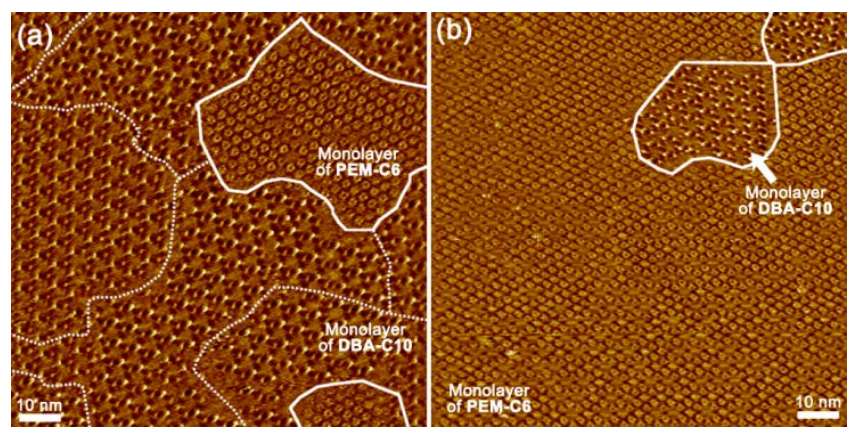

Figure 8. STM images of monolayers formed by a mixture of DBA-C10 $\left(1.0 \times 10^{-5} \mathrm{M}\right)$ and PEM-

C6 $\left(1.0 \times 10^{-5} \mathrm{M}\right)$ before annealing (a) and after annealing (b) at the TCB/graphite interface (tunneling parameters: $I_{\text {set }}=72 \mathrm{pA}$ and $V_{\text {set }}=-100 \mathrm{mV}$ for a, $I_{\text {set }}=72 \mathrm{pA}$ and $V_{\text {set }}=-160 \mathrm{mV}$ for b). White solid and dotted lines indicate the domain boundaries between the monolayers of DBA-C10 and PEM-C6 and the domain boundaries of the honeycomb structure of DBA-C10, respectively. 
Table 1. Distributions of Filled Pores, Partly Filled Pores, Fuzzy Pores, and Open Pores, and Phase

Behavior for Monolayers Formed by Combinations of DBA-TeEG/PEM-TEG, DBA-TeEG/PEM-

C6, DBA-H/PEM-TEG, and DBA-H/PEM-C6

\begin{tabular}{|c|c|c|c|c|c|c|c|c|}
\hline \multirow[b]{2}{*}{ compound } & \multirow{2}{*}{$\begin{array}{l}\text { mixing ratio } \\
\text { (DBA : PEM) }\end{array}$} & \multirow[b]{2}{*}{ annealing $^{a}$} & \multirow{2}{*}{$\begin{array}{c}\text { total } \\
\text { number of } \\
\text { pores }^{b}\end{array}$} & \multicolumn{4}{|c|}{ number of pores counted and its fraction (\%) } & \multirow[b]{2}{*}{ phase behavior } \\
\hline & & & & filled pores & $\begin{array}{c}\text { partly filled } \\
\text { pores }\end{array}$ & fuzzy pores & open pores & \\
\hline \multirow{4}{*}{$\begin{array}{c}\text { DBA- } \\
\text { TeEG/PEM } \\
\text {-TEG }\end{array}$} & \multirow{2}{*}{$1: 1$} & - & $\begin{array}{l}640 \\
(8)\end{array}$ & $\begin{array}{c}271 \\
(42 \pm 5 \%)\end{array}$ & $\begin{array}{c}45 \\
(7 \pm 3 \%)\end{array}$ & $\begin{array}{c}13 \\
(2 \pm 1 \%)\end{array}$ & $\begin{array}{c}311 \\
(49 \pm 5 \%)\end{array}$ & $\begin{array}{l}\text { preferential adsorption } \\
\text { (DBA) incorporating } \\
\text { guest }\end{array}$ \\
\hline & & + & $\begin{array}{l}1120 \\
(11)\end{array}$ & $\begin{array}{c}443 \\
(40 \pm 7 \%)\end{array}$ & $\begin{array}{c}56 \\
(5 \pm 3 \%)\end{array}$ & $\begin{array}{c}41 \\
(4 \pm 2 \%)\end{array}$ & $\begin{array}{c}580 \\
(51 \pm 6 \%)\end{array}$ & $\begin{array}{l}\text { preferential adsorption } \\
\text { (DBA) incorporating } \\
\text { guest }\end{array}$ \\
\hline & \multirow{2}{*}{$1: 2.6$} & - & $\begin{array}{l}712 \\
(13)\end{array}$ & $\begin{array}{c}338 \\
(47 \pm 7 \%)\end{array}$ & $\begin{array}{c}149 \\
(21 \pm 6 \%)\end{array}$ & $\begin{array}{c}12 \\
(2 \pm 3 \%)\end{array}$ & $\begin{array}{c}213 \\
(30 \pm 5 \%)\end{array}$ & $\begin{array}{l}\text { phase segregation } \\
(\mathrm{DBA} / \mathrm{PEM}=1 / 1)\end{array}$ \\
\hline & & + & $\begin{array}{l}396 \\
(5)\end{array}$ & $\begin{array}{c}239 \\
(60 \pm 3 \%)\end{array}$ & $\begin{array}{c}25 \\
(6 \pm 3 \%)\end{array}$ & $\begin{array}{c}5 \\
(1 \pm 1 \%)\end{array}$ & $\begin{array}{c}127 \\
(32 \pm 5 \%)\end{array}$ & $\begin{array}{l}\text { phase segregation } \\
(\mathrm{DBA} / \mathrm{PEM}=3 / 7)\end{array}$ \\
\hline \multirow{2}{*}{$\begin{array}{c}\text { DBA- } \\
\text { TeEG/PEM } \\
\text {-C6 }\end{array}$} & \multirow[t]{2}{*}{$1: 1$} & - & $\begin{array}{l}291 \\
(4)\end{array}$ & $\begin{array}{c}26 \\
(9 \pm 2 \%)\end{array}$ & $\begin{array}{c}10 \\
(3 \pm 2 \%)\end{array}$ & $\begin{array}{c}11 \\
(3 \pm 3 \%)\end{array}$ & $\begin{array}{c}244 \\
(85 \pm 3 \%)\end{array}$ & $\begin{array}{l}\text { phase segregation } \\
(\mathrm{DBA} / \mathrm{PEM}=7 / 3)\end{array}$ \\
\hline & & + & - & - & - & - & - & preferential adsorption (PEM) \\
\hline \multirow{4}{*}{$\begin{array}{l}\text { DBA-C10/ } \\
\text { PEM-TEG }\end{array}$} & \multirow{2}{*}{$1: 1$} & - & $\begin{array}{l}496 \\
(6)\end{array}$ & $\begin{array}{c}4 \\
(<1 \%)\end{array}$ & $\begin{array}{c}3 \\
(<1 \%)\end{array}$ & $\begin{array}{c}7 \\
(1 \pm 2 \%)\end{array}$ & $\begin{array}{c}482 \\
(97 \pm 2 \%)\end{array}$ & preferential adsorption (DBA) \\
\hline & & + & $\begin{array}{l}1103 \\
(11)\end{array}$ & $\begin{array}{c}9 \\
(1 \pm 1 \%)\end{array}$ & $\begin{array}{c}2 \\
(<1 \%)\end{array}$ & $\begin{array}{c}18 \\
(2 \pm 1 \%)\end{array}$ & $\begin{array}{c}1074 \\
(97 \pm 1 \%)\end{array}$ & preferential adsorption (DBA) \\
\hline & \multirow{2}{*}{$1: 2.6$} & - & $\begin{array}{l}353 \\
(9)\end{array}$ & $\begin{array}{c}4 \\
(1 \pm 1 \%)\end{array}$ & $\begin{array}{c}12 \\
(3 \pm 3 \%)\end{array}$ & $\begin{array}{c}14 \\
(4 \pm 4 \%)\end{array}$ & $\begin{array}{c}323 \\
(92 \pm 5 \%)\end{array}$ & $\begin{array}{l}\text { phase segregation } \\
(\mathrm{DBA} / \mathrm{PEM}=7 / 3)\end{array}$ \\
\hline & & + & $\begin{array}{l}750 \\
(14)\end{array}$ & $\begin{array}{c}15 \\
(2 \pm 3 \%)\end{array}$ & $\begin{array}{c}13 \\
(2 \pm 2 \%)\end{array}$ & $\begin{array}{c}32 \\
(4 \pm 4 \%)\end{array}$ & $\begin{array}{c}690 \\
(92 \pm 4 \%)\end{array}$ & $\begin{array}{l}\text { phase segregation } \\
(\mathrm{DBA} / \mathrm{PEM}=3 / 7)\end{array}$ \\
\hline \multirow{2}{*}{$\begin{array}{l}\text { DBA-C10/ } \\
\text { PEM-C6 }\end{array}$} & \multirow[t]{2}{*}{$1: 1$} & - & $\begin{array}{l}350 \\
(5)\end{array}$ & $\begin{array}{c}0 \\
(0 \%)\end{array}$ & $\begin{array}{c}0 \\
(0 \%)\end{array}$ & $\begin{array}{c}7 \\
(2 \pm 2 \%)\end{array}$ & $\begin{array}{c}343 \\
(98 \pm 2 \%)\end{array}$ & $\begin{array}{l}\text { phase segregation } \\
(\mathrm{DBA} / \mathrm{PEM}=9 / 1)\end{array}$ \\
\hline & & + & - & - & - & - & - & preferential adsorption (PEM) \\
\hline
\end{tabular}

${ }^{a}$ The + and - signs mean the conditions with or without annealing at $70{ }^{\circ} \mathrm{C}$ for $1 \mathrm{~h} .{ }^{b}$ The numbers of STM images analyzed are sown in parentheses. 
Guest occupancy in the porous space by electrostatic host-guest interaction. The results of STM observations are summarized in Table 1. Firstly, we discuss the different guest occupancies observed among the host-guest combinations. Because DBA-C10 did not exhibit marked guest immobilization toward either guest PEM-TEG or PEM-C6, we focus mainly on the effect of the peripheral functional group of the guest molecules PEM-TEG and PEM-C6 for co-adsorption in polar pores created by self-assembly of DBA-TeEG. In the DBA-TeEG/PEM-TEG host-guest combination, the co-adsorption rate of filled pores was 42\%, whereas that of the DBA-TeEG/PEMC6 combination was reduced to 9\%. To elucidate the driving force for the favorable co-adsorption of PEM-TEG, host-guest interaction energies of the DBA/PEM combinations were estimated by MM simulations on a graphene bilayer under the periodic boundary conditions ( $a=b=4.97 \mathrm{~nm}, \gamma=60.0^{\circ}$ ).

The orientation of the TeEG units of DBA-TeEG and the TEG units or alkyl chains of PEM-TEG or PEM-C6 could not be determined experimentally from the STM images due to limited resolution. Therefore, MM simulations were performed for the four initial structures which are different with respect to two geometrical elements: (1) which of the terminal chains, either the host matrix (the TeEG units of DBA-TeEG) or the guest (the TEG units of PEM-TEG or $\mathrm{C}_{6}$ chains of PEM-C6), are adsorbed on the surface and (2) the relative orientation (clockwise (CW) or anticlockwise (ACW)) of the TEG units or $\mathrm{C}_{6}$ chains of the guest with respect to that of the TeEG units of DBA-TeEG which is tentatively fixed to adopt the ACW orientation (Figures 9 for the DBA-TeEG/PEM-TEG 
combination and S14 for the DBA-TeEG/PEM-C6 combination).

Calculated intermolecular interactions are summarized in Table 2. $E_{\text {total }}$ stands for the noncovalent interaction energies of the entire system consisting of the molecular network of DBA, guest molecules, and the graphene bilayer including all internal, intermolecular, and molecule-substrate interactions. $E_{\text {host }}$ consists of two kinds of the noncovalent interaction energies, one for the molecular network of DBA without the graphene bilayer including internal and host-host, and the other for host-substrate interactions. $E_{\text {guest }}$ refers to the sum of the internal interaction of the guest molecule in itself without substrate and the interactions between the guest and substrate. From these values, the interaction energies between the host matrix and guest molecule, $E_{\text {host-guest }}=E_{\text {total }}-E_{\text {host }}-E_{\text {guest }}$, were calculated as shown in Table 2. The lower energy in Table 2 indicates stronger interactions. For the DBATeEG/PEM-TEG combination, the host-guest interaction energies are estimated to be in a range of -85.8 to $-100.3 \mathrm{kcal} / \mathrm{mol}$, while for the DBA-TeEG/PEM-C6 combination they range from -48.5 to $-64.6 \mathrm{kcal} / \mathrm{mol}$. Therefore, on the basis of MM simulations, even the energetically most unfavorable DBA-TeEG/PEM-TEG combination has host-guest interactions which are stronger by $20 \mathrm{kcal} / \mathrm{mol}$ than the most favorable geometry of the DBA-TeEG/PEM-C6 combination. It is considered that this difference of energetic stabilities is driven from dipole-dipole interactions between the ethylene glycol units of host and guest. ${ }^{63,64}$ Additionally, hydrogen bonds between the terminal OH group of the TeEG units of DBA-TeEG and the carbonyl or ether oxygen atoms of PEM-TEG ${ }^{65,66}$ would also 
contribute to the intermolecular interactions (indicated by yellow arrows in Figure 9a, 9b, and 9d), although the TeEG and TEG units are highly flexible when they are exposed to the solution phase. Moreover, to take into account the effect of solvent molecules adsorbed in the pores of different polarity, we estimated interaction energies between the host matrix and solvent molecules, $E_{\text {host-TCB, }}$ by MM simulations for models of the honeycomb networks of DBA-TeEG and DBA-C10 containing seven molecules of TCB in the pores. The geometries of the solvent molecules were optimized as

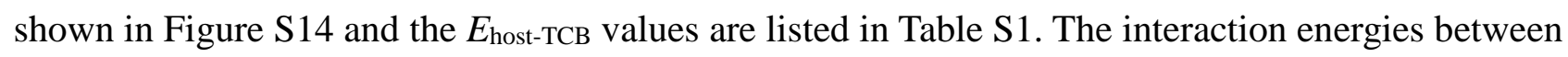
the host matrix and TCB molecules are -28.0 and $-26.1 \mathrm{kcal} / \mathrm{mol}$ for the monolayers of DBA-TeEG and DBA-C10, respectively. This indicates that (i) the host-solvent interactions are much smaller than the host-guest interactions ( $E_{\text {host-guest }}=-85.8$ to $-100.3 \mathrm{kcal} / \mathrm{mol}$ for DBA-TeEG/PEM-TEG and -48.5 to $-64.6 \mathrm{kcal} / \mathrm{mol}$ for DBA-TeEG/PEM-C6 (Table 2)) and (ii) the solvent molecules are slightly more stabilized in the matrix of DBA-TeEG than DBA-C10. However, in view of the significantly larger difference in the host-guest interaction energies between the two host-guest systems, the effect of competitive adsorption of solvent molecules can be neglected. Consequently, the higher guest occupancy for the DBA-TeEG/PEM-TEG combination compared to the DBATeEG/PEM-C6 combination is ascribed to electrostatic interactions, such as dipole-dipole and hydrogen bonding interactions, between the polar tails of the host and guest molecules. 

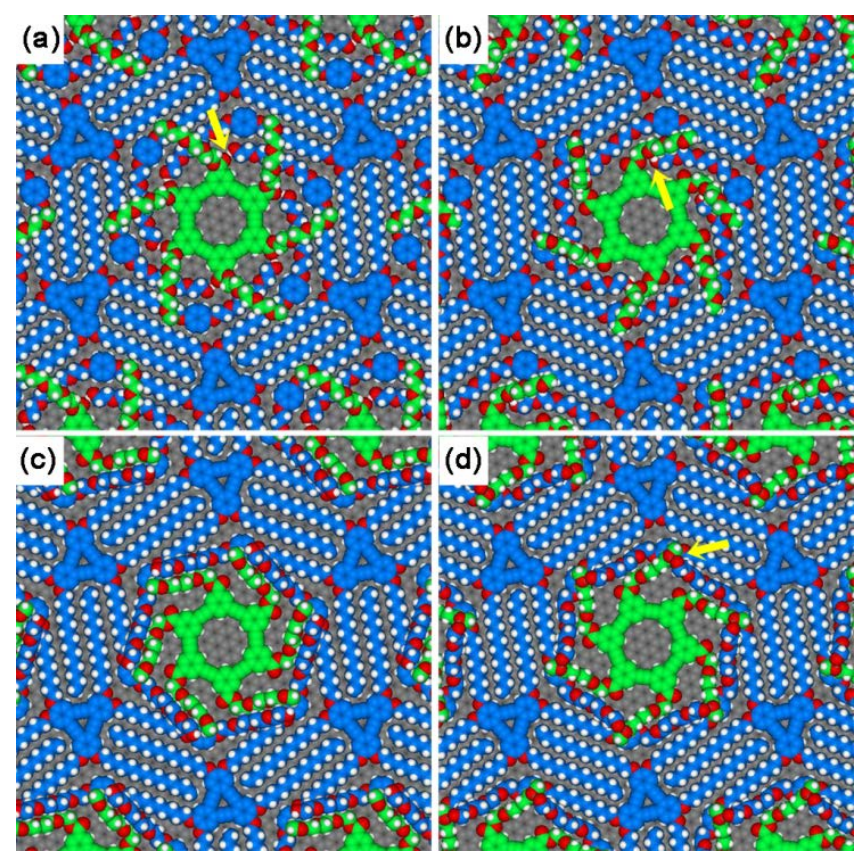

Figure 9. Molecular models optimized by COMPASS force field under periodic boundary conditions $\left(a=b=4.97 \mathrm{~nm}, \gamma=60^{\circ}\right)$ on a bilayer graphene for monolayers formed by a mixture of DBA-TeEG and PEM-TEG. (a) The TeEG units of DBA-TeEG being adsorbed and the TEG units of PEM-TEG adopting the same (ACW) orientation with respect to the TeEG units of DBA-TeEG. (b) The TeEG units of DBA-TeEG being adsorbed and the TEG units of PEM-TEG adopting the opposite (CW) orientation with respect to the TeEG units of DBA-TeEG. (c) The TeEG units of DBA-TeEG being desorbed and the TEG units of PEM-TEG adopting the same (ACW) orientation with respect to the TeEG units of DBA-TeEG. (d) The TeEG units of DBA-TeEG being desorbed and the TEG units of PEM-TEG adopting the opposite (CW) orientation with respect to the TeEG units of DBA-TeEG. The yellow arrows indicate one of hydrogen bonding sites between the terminal OH group of DBATeEG and the carbonyl oxygen of PEM-TEG. 
Table 2. Intermolecular Energies for Host-Guest Systems on Bilayered Graphene Sheet Calculated by MM Simulations Using COMPASS Force Field under Periodic Boundary Condition $(a=b=4.97$ $\left.\mathrm{nm}, \gamma=60.0^{\circ}\right)$

\begin{tabular}{|c|c|c|c|c|c|c|c|c|}
\hline \multirow[b]{3}{*}{ system } & \multicolumn{2}{|c|}{ geometry } & \multicolumn{5}{|c|}{ intermolecular energy ${ }^{c}(\mathrm{kcal} / \mathrm{mol})$} & \multirow[b]{3}{*}{$\begin{array}{c}E_{\text {host-guest }} f \\
(\mathrm{kcal} / \mathrm{mol})\end{array}$} \\
\hline & \multirow[b]{2}{*}{$\begin{array}{l}\text { TeEG unit of } \\
\text { DBA-TeEG }\end{array}$} & \multirow[b]{2}{*}{$\begin{array}{c}\text { TEG or } \mathrm{C}_{6} \text { unit } \\
\text { of PEM-TEG } \\
\text { or PEM-C6 }\end{array}$} & \multirow[b]{2}{*}{$E_{\text {total }}$} & \multicolumn{2}{|c|}{$E_{\text {host }}^{d}$} & \multicolumn{2}{|c|}{$E_{\text {guest }^{e}}$} & \\
\hline & & & & $\begin{array}{c}\text { nonbonding } \\
\text { interactions } \\
\text { without } \\
\text { substrate }\end{array}$ & $\begin{array}{c}\text { host-substrate } \\
\text { interaction }\end{array}$ & $\begin{array}{c}\text { nonbonding } \\
\text { interactions } \\
\text { without } \\
\text { substrate }\end{array}$ & $\begin{array}{c}\text { guest- } \\
\text { substrate } \\
\text { interaction }\end{array}$ & \\
\hline \multirow{4}{*}{$\begin{array}{c}\text { DBA- } \\
\text { TeEG/PEM- } \\
\text { TEG }\end{array}$} & \multirow{2}{*}{ adsorbed $^{a}$} & same $^{b}$ & -623.5 & 117.8 & -615.6 & 96.2 & -125.5 & -96.4 \\
\hline & & opposite $^{b}$ & -629.5 & 128.9 & -615.7 & 113.2 & -159.6 & -96.3 \\
\hline & \multirow{2}{*}{ desorbed $^{a}$} & same $^{b}$ & -568.8 & 115.3 & -529.5 & 102.3 & -171.1 & -85.8 \\
\hline & & opposite $^{b}$ & -556.5 & 104.1 & -496.3 & 141.3 & -205.3 & -100.3 \\
\hline \multirow{4}{*}{$\begin{array}{c}\text { DBA- } \\
\text { TeEG/PEM- } \\
\text { C6 }\end{array}$} & \multirow{2}{*}{ adsorbed $^{a}$} & same $^{b}$ & -667.2 & 119.9 & -616.9 & 20.9 & -126.5 & -64.6 \\
\hline & & opposite $^{b}$ & -662.3 & 119.8 & -616.3 & 21.2 & -138.5 & -48.5 \\
\hline & \multirow{2}{*}{ desorbed $^{a}$} & same $^{b}$ & -582.3 & 134.6 & -527.3 & 19.2 & -155.1 & -53.7 \\
\hline & & opposite $^{b}$ & -639.7 & 135.2 & -583.8 & 20.6 & -149.7 & -62.0 \\
\hline
\end{tabular}

${ }^{a}$ The TeEG units of DBA-TeEG are adsorbed on graphite or desorbed from it. ${ }^{b}$ The relative orientation ("same” for ACW or "opposite" for CW) of the TEG or $\mathrm{C}_{6}$ units of the guest with respect to that of the TeEG units of DBA-TeEG which adopt tentatively the ACW orientation. ${ }^{c}$ Sum of the intermolecular and molecule-substrate interaction energies. ${ }^{d} E_{\text {host }}$ was obtained by single point energy calculations for the host-guest systems in their optimized geometries which do not contain the guest molecules. ${ }^{e} E_{\text {guest }}$ was obtained by single point energy calculations for the host-guest systems in their optimized geometries which do not contain the host networks. ${ }^{f}$ Calculated by the following equation, $E_{\text {host-guest }}=E_{\text {total }}-E_{\text {host }}-E_{\text {guest }}$. 
In contrast to the host-guest events with the host network of DBA-TeEG described above, the nonpolar host matrix formed by DBA-C10 did not exhibit binding ability towards PEM-TEG and PEMC6. Even for the anticipated favorable DBA-C10/PEM-C6 combination in view of polarity matching, only phase separation and preferential adsorption were observed. This result is ascribed to the strong affinity between the guest molecules which form by themselves densely packed van der Waals networks on the surface as described in the following section.

Phase behavior of bicomponent systems. Next, phase behavior of the mixtures of DBAs and PEMs is discussed. On the basis of previously reported results of self-assembly at the liquid/solid interfaces, it is reasonable to assume that a kinetically trapped structure is observed before annealing treatment, whereas after annealing a thermodynamically stable phase is favored in the present system. ${ }^{57}$ We note that, in general, the honeycomb structures of DBAs with co-adsorbed TCB molecules are formed preferentially before annealing, whereas after annealing they are replaced by domains consisting of PEMs. Most typically, in the combination of DBA-C10/PEM-C6, most of the surface originally covered by DBA-C10 before annealing turned to be dominated by PEM-C6 after annealing. This result is probably due to co-adsorbed solvent (TCB) molecules in the honeycomb networks of DBAs; ${ }^{67,68}$ adsorption kinetics of the solvent molecules must be much faster that of the solute molecules because of the large excess amount of the solvent, favoring the porous structure 
kinetically.

Consequently, in the following discussion, we focus on STM observations after annealing. Although the formation of 2D co-crystal networks of DBAs and PEMs is possible in view of the presence of the phenylene-ethynylene units as a common structural unit, ${ }^{45,49}$ no such complementary networks were observed. This is due to due to mismatch of alkyl chain lengths between the building blocks. ${ }^{45}$ As a result, either preferential adsorption or phase segregation was observed. In the case of the mixture of DBA-TeEG and PEM-TEG, preferential adsorption of DBA-TeEG was observed at equimolar solution, while phase segregation took place only at higher molar ratio of PEM-TEG. The thermodynamic stability of the network of DBA-TeEG probably arises from favorable van der Waals interactions between the alkyl chains and the HOPG surface as well as intermolecular interactions between the interdigitated alkyl chains. To further estimate the relative stability, we calculated surface densities of the honeycomb structure of DBA-TeEG (without co-adsorbed solvent molecules) and the dense hexagonal and zigzag structures of PEM-TEG by dividing the number of adsorbed heavy atoms (non-hydrogen atoms) by the unit cell area used for molecular mechanics simulations. As a result, the surface density of the former was calculated to be $15.1 \mathrm{~nm}^{-2}$, whereas those of the latter were 18.3 and $15.3 \mathrm{~nm}^{-2}$ for the dense hexagonal and zigzag structures, respectively. Though the density of the hexagonal network of PEM-TEG is larger than that of DBA-TeEG, the alkyl chains in the latter building block contribute significantly to adsorption on the graphite surface. In contrast, 
in the network of PEM-TEG, the TEG side chains orient to the solution phase and do not participate in the network formation. ${ }^{33}$ On the other hand, using the mixture of DBA-TeEG and PEM-C6, preferential adsorption of PEM-C6 was observed, which is due to the higher density of the honeycomb structure of PEM-C6 (16.2 nm ${ }^{-2}$ ) compared to that of DBA-TeEG (15.1 nm $\left.{ }^{-2}\right)$. For the DBA-C10/PEM-TEG combination, DBA-C10 was adsorbed on the surface more preferentially compared to DBA-TeEG because all alkyl chains including the terminal $\mathrm{C}_{10}$ alkyl chains of DBAC10 contributed to adsorption, in spite of the lower density of the honeycomb structure of DBA-C10 (14.6 $\mathrm{nm}^{-2}$ ) than the monolayers of PEM-TEG (18.3 and $15.3 \mathrm{~nm}^{-2}$ ). Finally, in the case of the DBAC10/PEM-C6 combination, the latter was adsorbed preferentially due to the higher density network of PEM-C6 $\left(16.2 \mathrm{~nm}^{-2}\right)$ compared to that of DBA-C10 $\left(14.6 \mathrm{~nm}^{-2}\right)$. The dense van der Waals packing in the network of PEM-C6 is apparently more favorable than that of DBA-C10.

\section{SUMMARY AND CONCLUSIONS}

We have investigated the guest binding ability in highly polar pores created by self-assembly of DBA-TeEG bearing tetraethylene glycol units at the liquid/solid interface. Their self-assembled porous patterns act as host matrix toward the adsorption of hexagonal macrocyclic guests, i.e. PEMTEG and PEM-C6, with functional groups of different polarity, i.e. triethylene glycol units and hexyl chains, respectively. STM observations revealed that PEM-TEG was immobilized in the pores at 
higher probability due to electrostatic interactions such as dipole-dipole and hydrogen bonding interactions between oligoether units of the host and guest in comparison to PEM-C6 with non-polar groups. In addition, self-assembling behavior of opposite combination of polarity using a non-polar host matrix formed by DBA-C10 with the same guests, PEM-TEG and PEM-C6, was also investigated. However, only phase separation and preferential adsorption were observed; virtually no host-guest complexation was discernible even for the favorable polarity-matched combination of DBA-C10/PEM-C6. This is ascribed to the strong affinity between the guest molecules which form by themselves densely packed van der Waals networks on the surface. The present results provide useful insight toward the control of the 2D self-assembly of multicomponent mixtures.

\section{SUPPORTING INFORMATION}

Additional STM images and models, and synthetic details, ${ }^{1} \mathrm{H}$ and ${ }^{13} \mathrm{C}$ NMR spectra of DBA-TeEG.

This material is available free of charge via the Internet at http://pubs.acs.org.

\section{AUTHOR INFORMATION}

\section{Corresponding Authors}

* Phone: +217 544 5289. E-mail: jsmoore@illinois.edu (J.S.M.)

* Phone: +81 66879 8476. Fax: +81 66879 8479. E-mail: tobe@chem.es.osaka-u.ac.jp (Y.T.) 


\section{Notes}

The authors declare no competing financial interest.

\section{ACKNOWLEDGMENT}

This work is supported by JSPS KAKENHI Grant Numbers 2435004 and 15 H02164 and by the National Science Foundation CHE under Grant Number 16-10328. The authors would like to thank the School of Chemical Sciences NMR Lab and Mass Spectrometry Lab at University of Illinois at Urbana Champaign. S.D.F. thanks KU Leuven - internal funds, and FWO.

\section{REFERENCES}

(1) Samorí, P.; Rabe, J. P. Scanning Probe Microscopy Explorations on Conjugated (Macro)Molecular Architectures for Molecular Electronics. J. Phys.: Condens. Matter 2002, 14, 9955-9973.

(2) Barth, J. V.; Costantini, G.; Kern, K. Engineering Atomic and Molecular Nanostructures at Surfaces. Nature 2005, 437, 671-679.

(3) Wan, L. J. Fabricating and Controlling Molecular Self-Organization at Solid Surfaces: Studies by Scanning Tunneling Microscopy. Acc. Chem. Res. 2006, 39, 334-342.

(4) Barth, J. V. Molecular Architectonic on Metal Surfaces. Ann. Rev. Phys. Chem. 2007, 58, 375- 
407.

(5) Yang, Y. L.; Wang, C. Hierarchical Construction of Self-Assembled Low-Dimensional Molecular Architectures Observed by Using Scanning Tunneling Microscopy. Chem. Soc. Rev. 2009, 38, 25762589.

(6) Bonifazi, D.; Mohnani, S.; Llanes-Pallas, A. Supramolecular Chemistry at Interfaces: Molecular Recognition on Nanopatterned Porous Surfaces. Chem. - Eur. J. 2009, 15, 7004-7025.

(7) Kudernac, T.; Lei, S. B.; Elemans, J.; De Feyter, S. Two-Dimensional Supramolecular SelfAssembly: Nanoporous Networks on Surfaces. Chem. Soc. Rev. 2009, 38, 402-421.

(8) Zhang, X. M.; Zeng, Q. D.; Wang, C. Host-Guest Supramolecular Chemistry at Solid-Liquid Interface: An Important Strategy for Preparing Two-Dimensional Functional Nanostructures. Sci.

China: Chem. 2014, 57, 13-25.

(9) Teyssandier, J.; De Feyter, S.; Mali, K. S. Host-Guest Chemistry in Two-Dimensional Supramolecular Networks. Chem. Commun. 2016, 52, 11465-11487.

(10) Iritani, K.; Tahara, K.; De Feyter, S.; Tobe, Y. Host-Guest Chemistry in Integrated Porous Space Formed by Molecular Self-Assembly at Liquid-Solid Interfaces. Langmuir 2017, 3, 4601-4618.

(11) Cyr, D. M.; Venkataraman, B.; Flynn, G. W. STM Investigations of Organic Molecules Physisorbed at the Liquid-Solid Interface. Chem. Mater. 1996, 8, 1600-1615.

(12) De Feyter, S.; De Schryver, F. C. Two-Dimensional Supramolecular Self-Assembly Probed by 
Scanning Tunneling Microscopy. Chem. Soc. Rev. 2003, 32, 139-150.

(13) Yang, Y.; Wang, C. Hierarchical Construction of Self-Assembled Low-Dimensional Molecular Architectures Observed by Using Scanning Tunneling Microscopy. Chem. Soc. Rev. 2009, 38, 25762589.

(14) Tahara, K.; Gotoda, J.; Carroll, C. N.; Hirose, K.; De Feyter, S.; Tobe, Y. Square Tiling by Square Macrocycles at the Liquid/Solid Interface: Co-Crystallisation with One- or Two-Dimensional Order. Chem. - Eur. J. 2015, 21, 6806-6816.

(15) Ohira, A.; Sakata, M.; Hirayama, C.; Kunitake, M. 2D-Supramolecular Arrangements of Dibenzo-18-crown-6-ether and Its Inclusion Complex with Potassium Ion by Potential Controlled Adsorption. Org. Biomol. Chem. 2003, 1, 251-253.

(16) Yoshimoto, S.; Suto, K.; Tada, A.; Kobayashi, N.; Itaya, K. Effect of Adlayer Structure on the Host-Guest Recognition between Calcium and Crown-Ether-Slubstituted Phthalocyanine Arrays on Au Single-Crystal Surfaces. J. Am. Chem. Soc. 2004, 126, 8020-8027.

(17) Ciesielski, A.; Lena, S.; Masiero, S.; Spada, G. P.; Samorí, P. Dynamers at the Solid-Liquid Interface: Controlling the Reversible Assembly/Reassembly Process between Two Highly Ordered Supramolecular Guanine Motifs. Angew. Chem. Int. Ed. 2010, 49, 1963-1966.

(18) Thontasen, N.; Levita, G.; Malinowski, N.; Deng, Z.; Rauschenbach, S.; Kern, K. Grafting Crown Ether Alkali Host-Guest Complexes at Surfaces by Electrospray Ion Beam Deposition. J. Phys. 
Chem. C 2010, 114, 17768-17772.

(19) Schwab, M. G.; Takase, M.; Mavrinsky, A.; Pisula, W.; Feng, X. L.; Gamez, J. A.; Thiel, W.;

Mali, K. S.; De Feyter, S.; Müllen, K. Torands Revisited: Metal Sequestration and Self-Assembly of Cyclo-2,9-tris-1,10-phenanthroline Hexaaza Macrocycles. Chem. Eur. J. 2015, 21, 8426-8434.

(20) Hirsch, B. E.; Lee, S.; Qiao, B.; Chen, C. H.; McDonald, K. P.; Tait, S. L.; Flood, A. H. AnionInduced Dimerization of 5-Fold Symmetric Cyanostars in 3D Crystalline Solids and 2D SelfAssembled Crystals. Chem. Commun. 2014, 50, 9827-9830.

(21) Lee, S.; Hirsch, B. E.; Liu, Y.; Dobscha, J. R.; Burke, D. W.; Tait, S. L.; Flood, A. H. Multifunctional Tricarbazolo Triazolophane Macrocycles: One-Pot Preparation, Anion Binding, and Hierarchical Self-Organization of Multilayers. Chem. Eur. J. 2016, 22, 560-569.

(22) Stepanow, S.; Lingenfelder, M.; Dmitriev, A.; Spillmann, H.; Delvigne, E.; Lin, N.; Deng, X. B.; Cai, C. Z.; Barth, J. V.; Kern, K. Steering Molecular Organization and Host-Guest Interactions Using Two-Dimensional Nanoporous Coordination Systems. Nat. Mater. 2004, 3, 229-233.

(23) Perdigão, L. M. A.; Saywell, A.; Fontes, G. N.; Staniec, P. A.; Goretzki, G.; Phillips, A. G.; Champness, N. R.; Beton, P. H. Functionalized Supramolecular Nanoporous Arrays for Surface Templating. Chem. - Eur. J. 2008, 14, 7600-7607.

(24) Phillips, A. G.; Perdigão, L. M. A.; Beton, P. H.; Champness, N. R. Tailoring Pores for Guest Entrapment in a Unimolecular Surface Self-Assembled Hydrogen Bonded Network. Chem. Commun. 
2010, 46, 2775-2777.

(25) Räisänen, M. T.; Slater, A. G.; Champness, N. R.; Buck, M. Effects of Pore Modification on the Templating of Guest Molecules in a 2D Honeycomb Network. Chem. Sci. 2012, 3, 84-92.

(26) Tahara, K.; Katayama, K.; Blunt, M. O.; Iritani, K.; De Feyter, S.; Tobe, Y. Functionalized Surface-Confined Pores: Guest Binding Directed by Lateral Noncovalent Interactions at the SolidLiquid Interface. ACS Nano 2014, 8, 8683-8694.

(27) Uchida, T.; Kurita, Y.; Koizumi, N.; Kubo, M. Dipole Moments and the Structures of Polyethylene Glycols. J. Polym. Sci. 1956, 21, 313-322.

(28) Kimura, K.; Fujishiro, R. The Dipole Moments of the Oligether of Ethylene Glycol. Bull. Chem. Soc. J. 1966, 39, 608-610.

(29) Carrillo, R.; Morales, E. Q.; Martin, V. S.; Martin, T. Correlation between Conformational Equilibria of Free Host and Guest Binding Affinity in Non-Preorganized Receptors. J. Org. Chem. 2013, 78, 7785-7795.

(30) Morimoto, N.; Muramatsu, K.; Nomura, S. M.; Suzuki, M. Trading Polymeric Microspheres: Exchanging DNA Molecules via Microsphere Interaction. Colloids Surf., B 2015, 128, 94-99.

(31) Bakaic, E.; Smeets, N. M. B.; Barrigar, O.; Alsop, R.; Rheinstadter, M. C.; Hoare, T. pHIonizable in Situ Gelling Poly(oligo ethylene glycol methacrylate)-Based Hydrogels: The Role of Internal Network Structures in Controlling Macroscopic Properties. Macromolecules 2017, 50, 7687- 
7698.

(32) Lahiri, S.; Thompson, J. L.; Moore, J. S. Solvophobically Driven $\pi$-Stacking of Phenylene Ethynylene Macrocycles and Oligomers. J. Am. Chem. Soc. 2000, 122, 11315-11319.

(33) Iritani, K.; Ikeda, M.; Yang, A. N.; Tahara, K.; Hirose, K.; Moore, J. S.; Tobe, Y. Hexagonal Molecular Tiling by Hexagonal Macrocycles at the Liquid/Solid Interface: Structural Effects on Packing Geometry. Langmuir 2017, 33, 12453-12462.

(34) Ruben, M.; Payer, D.; Landa, A.; Comisso, A.; Gattinoni, C.; Lin, N.; Collin, J. P.; Sauvage, J. P.; De Vita, A.; Kern, K. 2D Supramolecular Assemblies of Benzene-1,3,5-triyl-tribenzoic Acid: Temperature-Induced Phase Transformations and Hierarchical Organization with Macrocyclic Molecules. J. Am. Chem. Soc. 2006, 128, 15644-15651.

(35) Lee, S. L.; Fang, Y.; Velpula, G.; Cometto, F. R.; Lingenfelder, M.; Müllen, K.; Mali, K. S.; De Feyter, S. Reversible Local and Global Switching in Multicomponent Supramolecular Networks: Controlled Guest Release and Capture at the Solution/Solid Interface. ACS Nano 2015, 9, 1160811617.

(36) Lei, S. B.; Tahara, K.; Feng, X. L.; Furukawa, S. H.; De Schryver, F. C.; Müllen, K.; Tobe, Y.; De Feyter, S. Molecular Clusters in Two-Dimensional Surface-Confined Nanoporous Molecular Networks: Structure, Rigidity, and Dynamics. J. Am. Chem. Soc. 2008, 130, 7119-7129.

(37) Baker, R. T.; Mougous, J. D.; Brackley, A.; Patrick, D. L. Competitive Adsorption, Phase 
Segregation, and Molecular Motion at a Solid-Liquid Interface Studied by Scanning Tunneling Microscopy. Langmuir 1999, 15, 4884-4891.

(38) Kim, K.; Plass, K. E.; Matzger, A. J. Structure of and Competitive Adsorption in Alkyl Dicarbamate Two-Dimensional Crystals. J. Am. Chem. Soc. 2005, 127, 4879-4887.

(39) Palma, C. A.; Bjork, J.; Bonini, M.; Dyer, M. S.; Llanes-Pallas, A.; Bonifazi, D.; Persson, M.; Samorí, P. Tailoring Bicomponent Supramolecular Nanoporous Networks: Phase Segregation, Polymorphism, and Glasses at the Solid-Liquid Interface. J. Am. Chem. Soc. 2009, 131, 13062-13071. (40) Venkataraman, B.; Breen, J. J.; Flynn, G. W. Scanning Tunneling Microscopy Studies of Solvent Effects on the Adsorption and Mobility of Triacontane/Triacontanol Molecules Adsorbed on Graphite. J. Phys. Chem. 1995, 99, 6608-6619.

(41) Castro, M. A.; Clarke, S. M.; Inaba, A.; Thomas, R. K.; Arnold, T. Preferential Adsorption from Binary Mixtures of Short Chain n-Alkanes; The Octane-Decane System. J. Phys. Chem. B 2001, 105, 8577-8582.

(42) Yablon, D. G.; Ertas, D.; Fang, H. B.; Flynn, G. W. An STM Investigation of the Adsorption of Mixtures of Fatty Acids and Substituted Acids at the Solution-Graphite Interface. Isr. J. Chem. 2003, 43, 383-392.

(43) Xie, Z. X.; Xu, X.; Mao, B. W.; Tanaka, K. Self-Assembled Binary Monolayers of n-Alkanes on Reconstructed Au(111) and HOPG Surfaces. Langmuir 2002, 18, 3113-3116. 
(44) Palma, C. A.; Samorí, P.; Cecchini, M. Atomistic Simulations of 2D Bicomponent SelfAssembly: From Molecular Recognition to Self-Healing. J. Am. Chem. Soc. 2010, 132, 17880-17885.

(45) Lei, S. B.; Tahara, K.; Müllen, K.; Szabelski, P.; Tobe, Y.; De Feyter, S. Mixing Behavior of Alkoxylated Dehydrobenzo[12]annulenes at the Solid-Liquid Interface: Scanning Tunneling Microscopy and Monte Carlo Simulations. ACS Nano 2011, 5, 4145-4157.

(46) Theobald, J. A.; Oxtoby, N. S.; Phillips, M. A.; Champness, N. R.; Beton, P. H. Controlling Molecular Deposition and Layer Structure with Supramolecular Surface Assemblies. Nature 2003, 424, 1029-1031.

(47) Kampschulte, L.; Griessl, S.; Heckl, W. M.; Lackinger, M. Mediated Coadsorption at the LiquidSolid Interface: Stabilization through Hydrogen Bonds. J. Phys. Chem. B 2005, 109, 14074-14078.

(48) Wei, Y. H.; Tong, W. J.; Wise, C.; Wei, X. L.; Armbrust, K.; Zimmt, M. Dipolar Control of Monolayer Morphology: Spontaneous SAM Patterning. J. Am. Chem. Soc. 2006, 128, 13362-13363.

(49) Jester, S. S.; Sigmund, E.; Höger, S. Nanopatterning by Molecular Polygons. J. Am. Chem. Soc. 2011, 133, 11062-11065.

(50) Nguyen, D. C. Y.; Smykalla, L.; Nguyen, T. N. H.; Mehring, M.; Hietschold, M. Role of the Deposition Temperature on the Self-Assembly of the Non-Planar Molecule Benzene-1,3,5triphosphonic Acid (BTP) at the Liquid-Solid Interface. Phys. Chem. Chem. Phys. 2016, 18, 2421924227. 
(51) Lu, J.; Lei, S. B.; Zeng, Q. D.; Kang, S. Z.; Wang, C.; Wan, L. J.; Bai, C. L. Template-Induced Inclusion Structures with Copper(II) Phthalocyanine and Coronene as Guests in Two-Dimensional Hydrogen-Bonded Host Networks. J. Phys. Chem. B 2004, 108, 5161-5165.

(52) Griessl, S. J. H.; Lackinger, M.; Jamitzky, F.; Markert, T.; Hietschold, M.; Heckl, W. A. Incorporation and Manipulation of Coronene in an Organic Template Structure. Langmuir 2004, 20, 9403-9407.

(53) Schull, G.; Douillard, L.; Fiorini-Debuisschert, C.; Charra, F.; Mathevet, F.; Kreher, D.; Attias, A. J. Single-Molecule Dynamics in a Self-Assembled 2D Molecular Sieve. Nano Lett. 2006, 6, 13601363.

(54) Li, M.; Deng, K.; Lei, S. B.; Yang, Y. L.; Wang, T. S.; Shen, Y. T.; Wang, C. R.; Zeng, Q. D.; Wang, C. Site-Selective Fabrication of Two-Dimensional Fullerene Arrays by Using a Supramolecular Template at the Liquid-Solid Interface. Angew. Chem. Int. Ed. 2008, 47, 6717-6721.

(55) Shen, M. Q.; Luo, Z. Y.; Zhang, S. Q.; Wang, S.; Cao, L. L.; Geng, Y. F.; Deng, K.; Zhao, D. H.; Duan, W. B.; Zeng, Q. D. A Size, Shape and Concentration Controlled Self-Assembling Structure with Host-Guest Recognition at the Liquid-Solid Interface Studied by STM. Nanoscale 2016, 8, 11962-11968.

(56) Velpula, G.; Takeda, T.; Adisoejoso, J.; Inukai, K.; Tahara, K.; Mali, K. S.; Tobe, Y.; De Feyter, S. On the Formation of Concentric 2D Multicomponent Assemblies at the Solution-Solid Interface. 
Chem. Commun. 2017, 53, 1108-1111.

(57) Mazur, U.; Hipps, K. W. Kinetic and Thermodynamic Processes of Organic Species at the Solution-Solid Interface: The View through an STM. Chem. Commun. 2015, 51, 4737-4749.

(58) Lazzaroni, R.; Calderone, A.; Lambin, G.; Rabe, J. P.; Bredas, J. L. A Theoretical Approach to the STM Imaging of Adsorbates on the Graphite Surface. Synth. Met. 1991, 41, 525-528.

(59) Faglioni, F.; Claypool, C. L.; Lewis, N. S.; Goddard, W. A. Theoretical Description of the STM Images of Alkanes and Substituted Alkanes Adsorbed on Graphite. J. Phys. Chem. B 1997, 101, 5996-6020.

(60) Papadantonakis, K. A.; Brunschwig, B. S.; Lewis, N. S. Use of Alkane Monolayer Templates to Modify the Structure of Alkyl Ether Monolayers on Highly Ordered Pyrolytic Graphite. Langmuir 2008, 24, 857-861.

(61) Mamdouh, W.; Uji-i, H.; Ladislaw, J. S.; Dulcey, A. E.; Percec, V.; De Schryver, F. C.; De Feyter, S. Solvent Controlled Self-Assembly at the Liquid-Solid Interface Revealed by STM. J. Am. Chem. Soc. 2006, 128, 317-325.

(62) Ghijsens, E.; Cao, H.; Noguchi, A.; Ivasenko, O.; Fang, Y.; Tahara, K.; Tobe, Y.; De Feyter, S. Towards Enantioselective Adsorption in Surface-Confined Nanoporous Systems. Chem. Commun. 2015, 51, 4766-4769.

(63) Mohren, S.; Heintz, A. Excess Properties of Propan-1-ol + Polyether and Propan-1-ol + 
Polyamine Mixtures. Experimental Results of $H^{\mathrm{E}}$ and $V^{\mathrm{E}}$ and Application of a Multiple CrossAssociation Theory Based on the ERAS Model. Fluid Phase Equilib. 1997, 133, 247-264.

(64) Champagne, P. L.; Ester, D.; Ward, S.; Williams, V. E.; Ling, C. C. A Family of Amphiphilic Cyclodextrin Liquid Crystals Governed by Dipole-Dipole Interactions. ChemPlusChem 2017, 82, 423-432.

(65) Prabhumirashi, L. S.; Jose, C. I. Infra-Red Studies and Thermodynamics of Hydrogen-Bonding in Ethylene Glycol Monoalkyl Ethers. Evidence for a Ten Membered Ring Dimer. J. Chem. Soc., Faraday Trans. 2 1975, 71, 1545-1554.

(66) Philippova, O. E.; Kuchanov, S. I.; Topchieva, I. N.; Kabanov, V. A. Hydrogen Bonds in Dilute Solutions of Poly(ethylene glycol). Macromolecules 1985, 18, 1628-1633.

(67) Tahara, K.; Furukawa, S.; Uji-i, H.; Uchino, T.; Ichikawa, T.; Zhang, J.; Mamdouh, W.; Sonoda, M.; De Schryver, F. C.; De Feyter, S.; Tobe, Y. Two-Dimensional Porous Molecular Networks of Dehydrobenzo[12]annulene Derivatives via Alkyl Chain Interdigitation. J. Am. Chem. Soc. 2006, 128, $16613-16625$.

(68) Blunt, M. O.; Adisoejoso, J.; Tahara, K.; Katayama, K.; Van der Auweraer, M.; Tobe, Y.; De Feyter, S. Temperature-Induced Structural Phase Transitions in a Two-Dimensional Self-Assembled Network. J. Am. Chem. Soc. 2013, 135, 12068-12075. 
TOC

$H+M$

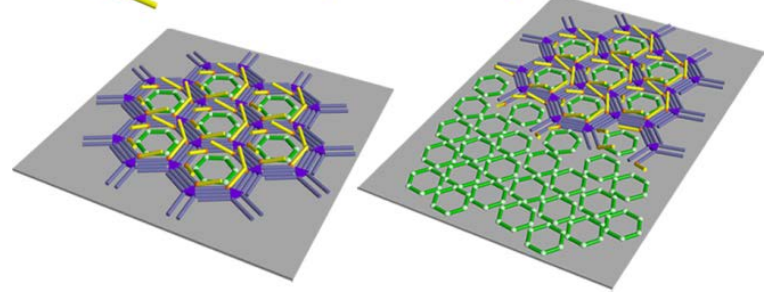

